\title{
BMJ Open What attributions do Australian high- performing general practices make for their success? Applying the clinical microsystems framework: a qualitative study
}

\author{
Annette H Dunham, ${ }^{1}$ James A Dunbar, ${ }^{2}$ Julie K Johnson, ${ }^{3}$ Jeff Fuller, ${ }^{4}$ \\ Mark Morgan, ${ }^{5}$ Dale Ford ${ }^{6}$
}

To cite: Dunham AH, Dunbar JA Johnson JK, et al. What attributions do Australian high-performing general practices make for their success? Applying the clinical microsystems framework: a qualitative study. BMJ Open 2018;8:e020552. doi:10.1136/ bmjopen-2017-020552

- Prepublication history and additional material for this paper are available online. To view these files, please visit the journal online (http://dx.doi org/10.1136/bmjopen-2017020552).

Received 8 November 2017 Revised 24 January 2018 Accepted 27 February 2018
Check for updates

For numbered affiliations see end of article.

Correspondence to

Dr Annette H Dunham;

a.dunham@auckland.ac.nz

\section{ABSTRACT}

Objectives To identify the success attributions of highperforming Australian general practices and the enablers and barriers they envisage for practices wishing to emulate them.

Design Qualitative study using semi-structured interviews and content analysis of the data. Responses were recorded, transcribed verbatim and coded according to success characteristics of high-performing clinical microsystems.

Setting Primary healthcare with the participating general practices representing all Australian states and territories, and representing metropolitan and rural locations. Participants Twenty-two general practices identified as high performing via a number of success criteria. The 52 participants were 19 general practitioners, 18 practice managers and 15 practice nurses.

Results Participants most frequently attributed success to the interdependence of the team members, patientfocused care and leadership of the practice. They most often signalled practice leadership, team interdependence and staff focus as enablers that other organisations would need to emulate their success. They most frequently identified barriers that might be encountered in the form of potential deficits or limitations in practice leadership, staff focus and mesosystem support.

Conclusions Practice leaders need to empower their teams to take action through providing inclusive leadership that facilitates team interdependence. Mesosystem support for quality improvement in general practice should focus on enabling this leadership and team building, thereby ensuring improvement efforts are converted into effective healthcare provision.

\section{INTRODUCTION}

Rising healthcare costs and ageing populations with chronic diseases stretch the resources of health budgets everywhere. Cardiovascular disease, cancers, chronic respiratory diseases and diabetes are the world's biggest killers causing 14 million deaths annually in people between the ages
Strengths and limitations of this study

- The study focused on high-performing general practices identified through objective criteria.

- The study included general practitioner, practice manager and practice nurse perspectives.

- All practices had participated in the Australian Primary Care Collaboratives Programme, which may restrict the generalisability of the findings.

of 30 and 70 years. WHO member states have agreed to reduce non-communicable diseases by $25 \%$ by $2025 .^{1}$

General practice plays a major role in prevention by promoting smoking cessation, identification and management of risks for diabetes and cardiovascular disease. ${ }^{2}$ Not surprisingly, governments have made efforts to improve the performance of general practice. Over the last 25 years, we have seen mesolevel Primary Healthcare Organisations (PHOs) developing in Australia, Canada, the Netherlands, New Zealand, the UK and the USA. The purpose of these mesolevel PHOs is to implement governmental health policies locally by supporting general practices. Evidence about their effectiveness in supporting change in general practice is mixed. $^{3-9}$

Other initiatives have included learning collaborative approaches, which were first tried in the UK primary care and later in Australia, Canada and north-west Europe. ${ }^{10} 11$ They proved successful but funding was short lived. By comparison with total health expenditure, organisational developmental efforts have been small and mostly directed at providing individual education opportunities even though there is growing recognition that training individuals does not result 
in improvement unless organisational culture itself also changes. ${ }^{12}$

The aims of this study were to identify success characteristics in high-performing Australian general practices and to note enablers and barriers that other organisations wishing to achieve similar success should consider. These were categorised according to known success characteristics of high-performing microsystems. ${ }^{13}$ Clinical microsystems are the smallest clinical unit where patients and their families access care, for example, a general practice. The performance of the mesosystem can be no better than the sum of the performances of the microsystems, its building blocks. The microsystem concept has roots in the work of Deming, Senge and Wheatley, who applied systems thinking to organisational development, leadership and improvement. ${ }^{13}$ Quinn in $1992^{14}$ applied the idea of a 'smallest replicable unit' (p.13) ${ }^{13}$ to high-performing service organisations whom he saw successfully organised around and engineered their frontline interface with individual customer needs, opening the way for its application within healthcare. ${ }^{13}$

The success characteristics of high-performing clinical microsystems were identified in a study of 20 best-quality, best-value small clinical units in North America. ${ }^{13}$ Work in applying the microsystem concept in North America and in Europe has resulted in a set of tools to drive quality improvement through team and organisational development. ${ }^{15}$ The success characteristics included leadership, mesosystem support of the microsystems, patient focus, community and market focus, staff focus, education and training, interdependence of the care team, information and information technology, process improvement and performance results. These characteristics formed the basis of our analysis of high-performing Australian general practices.

\section{METHODS}

The study was designed to elicit individual perspectives on reasons for the success of high-performing practices. We were interested in how these success factors aligned with a pre-existing framework of success characteristics in clinical microsystems. ${ }^{13}$ The study applied an interpretive theoretical approach. Interpretive studies 'assume that people create and associate their own subjective and intersubjective meanings as they interact with the world around them' (p. 5) ${ }^{16}$ and in this study we accept that this includes both participants and researchers. Ethics approval for the study was obtained from the Flinders University Social and Behavioural Research Ethics Committee.

\section{Study sample and recruitment}

Several filters were used to select high-performing general practice clinical microsystems. A national purposive sample of 26 practices was selected using the following: (1) identification of award winners by Australian General Practice Accreditation Limited (AGPAL), a provider of accreditation and quality improvement for general practices. Awards were for safety, innovation, consumer participation and practice of the year. We also sought recommendation from AGPAL staff based on surveyors' practice accreditation visits or 'Best within Best' from AGPAL nominations of high-performing practices over and above the prize winners. AGPAL states 'Practices across Australia continue to implement quality improvements within their practice to improve efficiencies, processes, staff and patient engagement. We share these industry achievements with other practices and stakeholders to recognise, cultivate and maintain a community of quality'. ${ }^{17}$ (2) Performance in the Australian Primary Care Collaboratives (APCC) supported by recommendations from APCC staff. Entry to the Collaboratives required practices to already have managers, nurses, computer systems and evidence of interest in quality improvement. Hence, our consideration of quality was by virtue of reputation and participation in quality processes.

Twenty-six practices were approached to participate in the staff interviews via email and phone by a medically trained, male postdoctoral fellow with no prior relationship with the practices. Twenty-two of the 26 practices agreed to participate. The interviews were conducted by the postdoctoral fellow (alone), with limited prior experience of the topic; he in turn was supported by three members of the research team steeped in the research and practice of quality improvement in primary care.

\section{Data collection and analysis}

The research team developed an interview schedule to focus on four broad areas: the contribution of the APCC on team dynamics and practice nurse roles, characteristics of high-performing general practices and leadership and cultural characteristics associated with high performance (see questionnaire in online supplementary appendix A). Participants were apprised of the aims of the research and gave written informed consent. Semi-structured interviews ranging from 20 to $60 \mathrm{~min}$ duration were conducted in a confidential manner at each participating practice by the postdoctoral fellow. Interviews were audio recorded and transcribed verbatim. Field notes were made only sporadically and offered brief impressions of practice environments and interactions. Cognisant of the time demands on participants, interviews were not returned to participants for comment and no repeat interviews were carried out. The time frame of the study meant that the data collection had to be completed before data analysis could progress.

The approach to content analysis was to use the $a$ priori framework of the research questions as well as to apply a microsystems framework to categorise emergent concepts. The focal question for this study centred on participant perspectives of why their practices might be considered 'high performing' and, if time permitted, most participants were also asked about the enablers and barriers that other practices would need to consider if they were to replicate their model: 
Table 1 Participating general practices

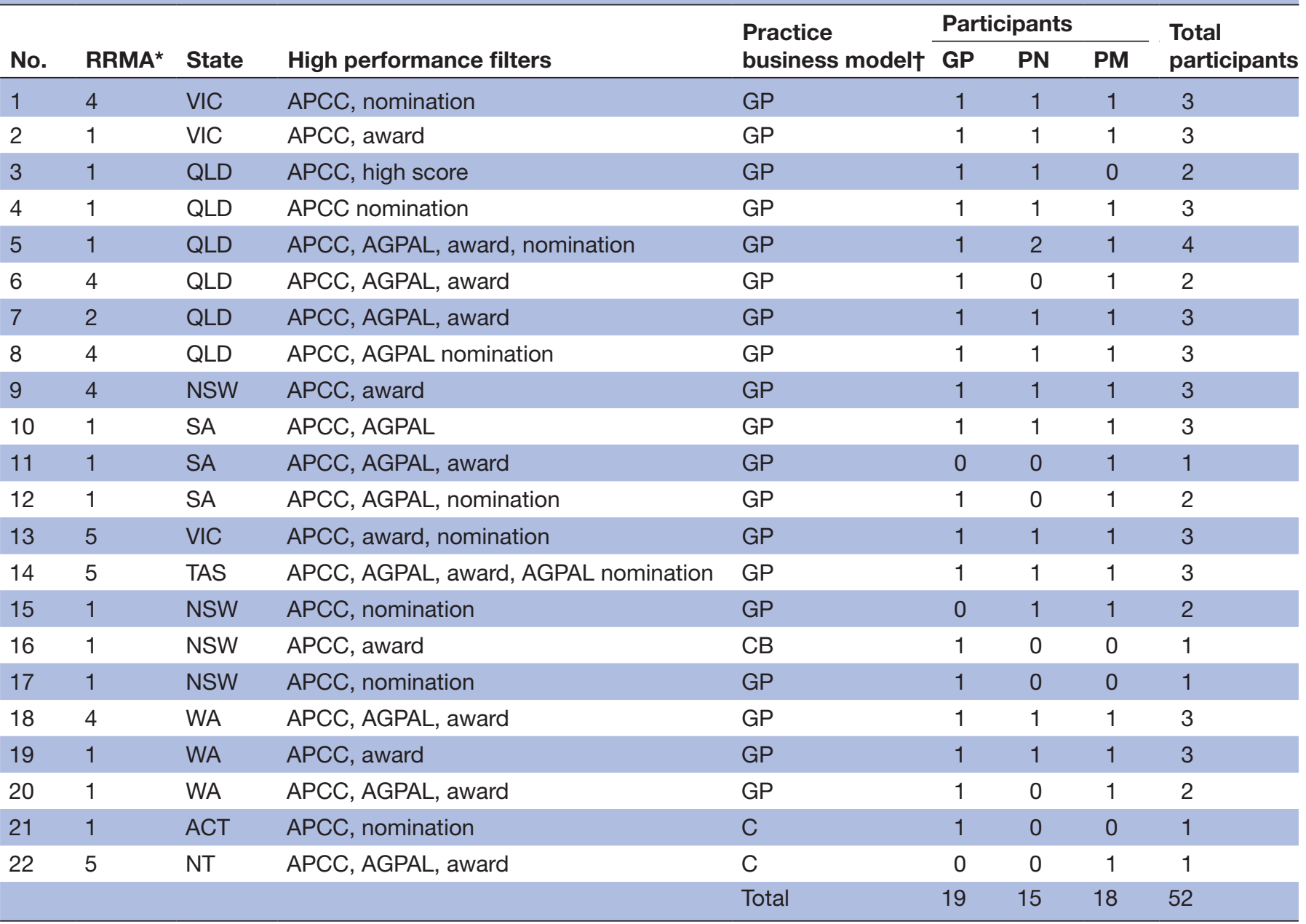

*RRMA refers to the Rural, Remote and Metropolitan Areas classification. 1=capital cities, 2=other metropolitan areas, 3=large rural areas, $4=$ small rural areas, $5=$ other rural (not including remote).

†Business model refers to practice ownership: corporate (C), community board (CB) or GP owned (GP).

AGPAL, Australian General Practice Accreditation Limited; APCC, Australian Primary Care Collaboratives; GP, general practitioner; PM, practice manager; PN, practice nurse.

What are the things that this practice does that has enabled you to achieve this level of performance?

What do you think it would take to replicate what you are doing? What do you think are the key factors to your success - the key lessons for others who would like to replicate what you have done?

What are the major barriers to replicating this elsewhere? What barriers have you overcome?

The first author coded the transcripts using a deductive approach based on the success characteristics of high-performing clinical microsystems. ${ }^{13}$ QSR International's NVivo V.11 Software was used to facilitate coding and indexing the data. ${ }^{18}$

\section{RESULTS}

Twenty-two practices participated in the study. The interviewer conducted 52 interviews with 19 general practitioners (GPs), 15 practice nurses and 18 practice managers from April to December 2013. All Australian states and territories were represented in the study (table 1).

\section{Identifying success characteristics}

Interview transcripts were coded according to the clinical microsystem success characteristics (see table 2 for representative quotes); (see also online supplementary appendix B for further summaries of responses for each characteristic). Once completed, the attributions coded to each specific microsystem success characteristic were summed and classified according to profession (figure 1).

\section{Frequency of attributions for success and differences by professional group}

Overall, the most frequently coded success characteristic was interdependence which was referred to in similar proportions by the three professional groups. This was followed closely by patient focus. The least coded success characteristic was community and market focus. 


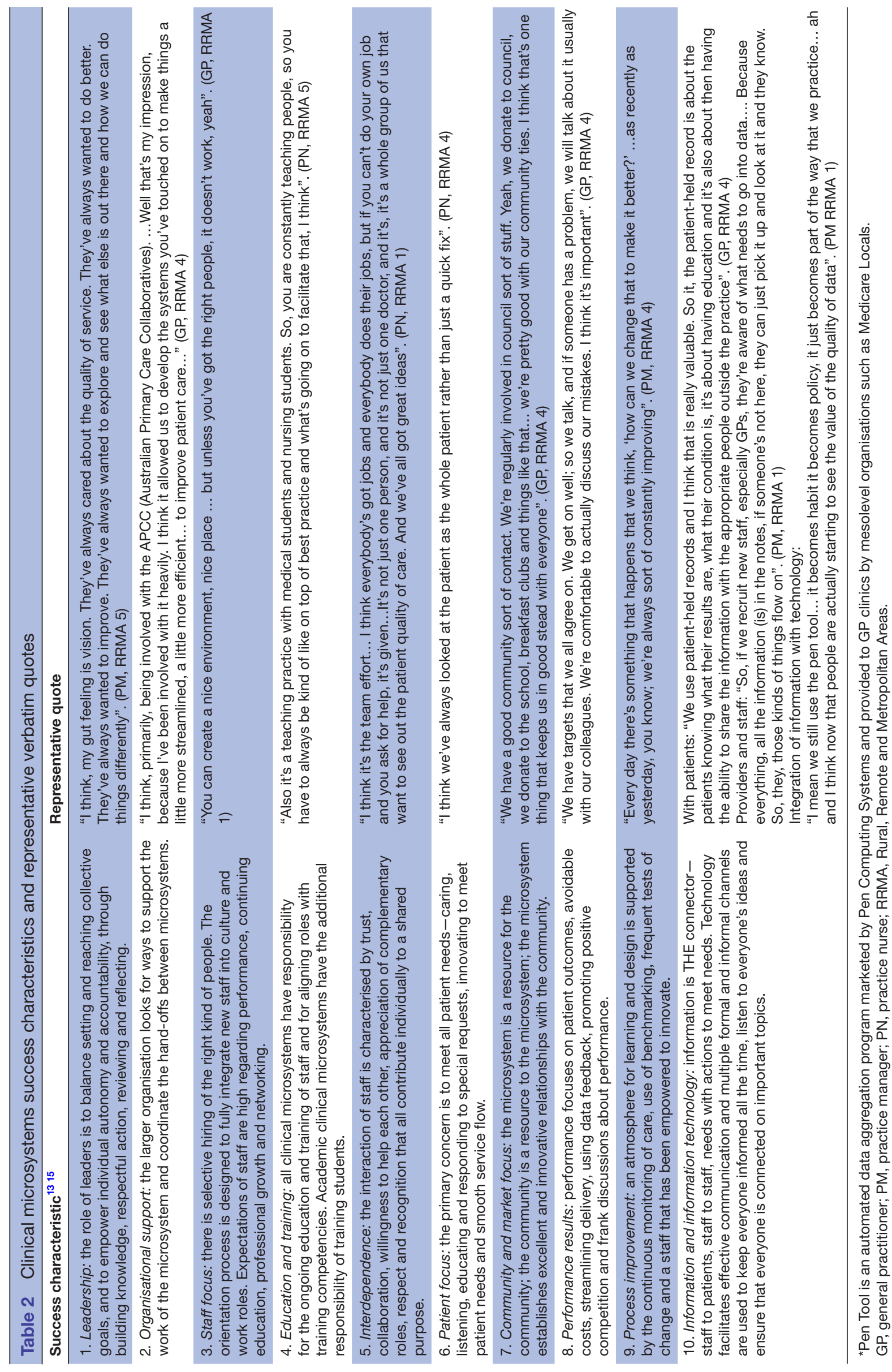

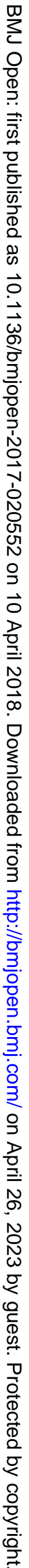




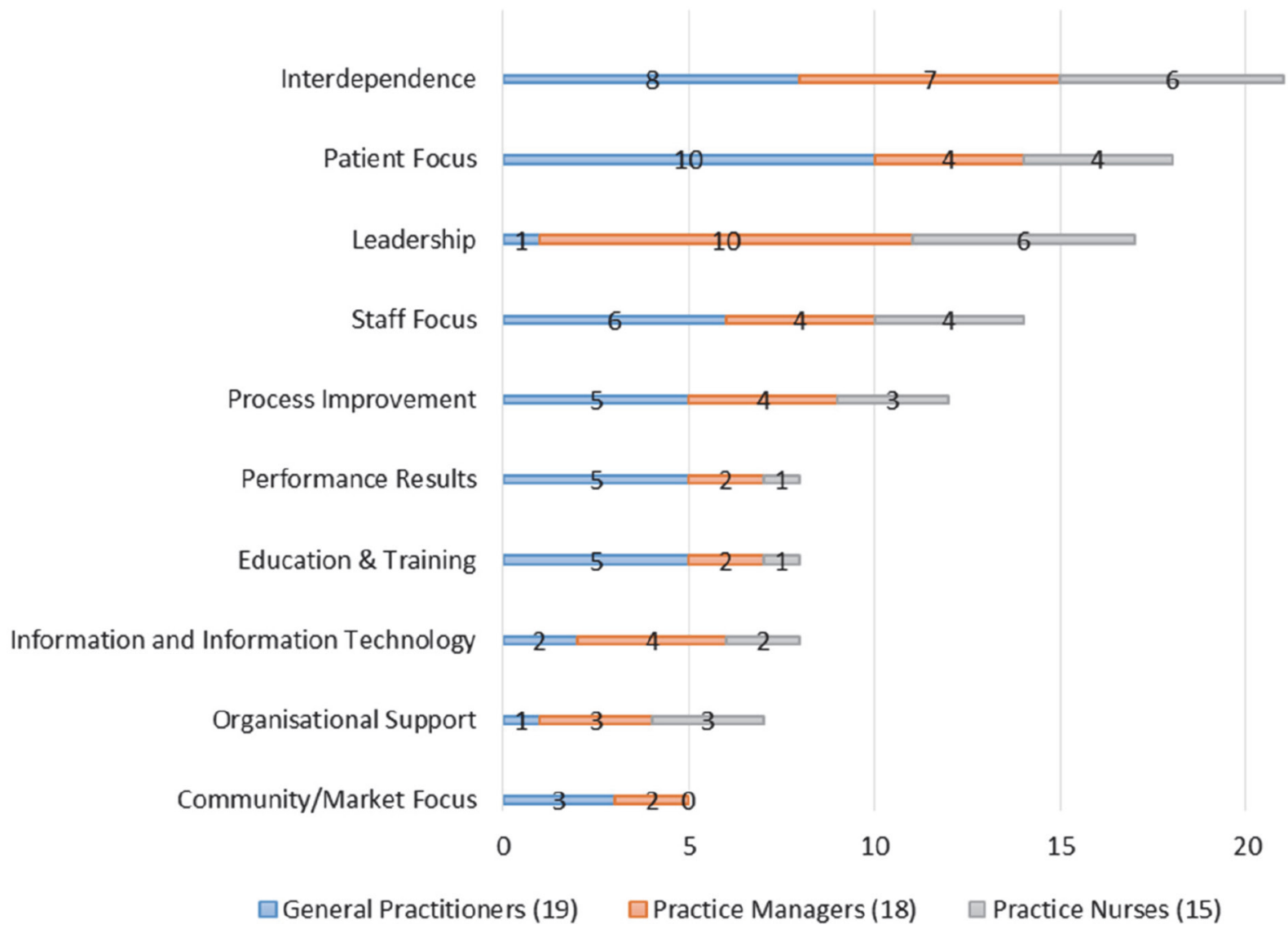

Practice nurses' attributions of success were equally most frequently coded under leadership and interdependence. Practice managers followed a similar pattern with their explanations coded most frequently under leadership, followed by interdependence. The most frequently coded success characteristic among GPs was patient focus followed by interdependence. The least coded success characteristic for practice nurses was community and market focus, while performance results, community and market focus and education and training featured equally the least for practice managers. The least cited success characteristics for GPs were leadership and organisational support.

\section{'We are not perfect'}

While most participants readily accepted their 'high-performing' label, there were a couple of exceptions. The first noted the importance of continuous learning:

I'm going to be honest: we're not perfect ...Some I think are more up to date than others and that's a reflection of maybe professional development, teaching students, courses, conferences; some will do more than others. (GP, RRMA 4)

Another while dodging the label 'high-performing' highlighted the importance of being focused on patient care:
I didn't know that we were so high performing, let's put it that way. I guess what we want to do is we want to achieve the maximum of the patient outcomes, you know, patient care. That's what we're all there for, you know, all the doctors are there for. We don't want to be just ticking along and doing a job and going home. (GP RRMA 5)

\section{Identifying enablers and barriers}

Of the 52 participants, 41 individuals representing 18 practices were asked questions about barriers and enablers that might impact on other practices wishing to emulate their success. Enablers and barriers were coded under the clinical microsystems success characteristics (see table 3 for representative quotes). Barriers were couched in terms of deficits in, or limitations of the success characteristics. Further summaries of the responses can be found in online supplementary appendix C.

Enabler responses were most frequently coded under leadership, interdependence and staff focus; the least frequently coded were performance results, community and market focus and education and training (figure 2). GP nominated enablers were most frequently coded under leadership (in contrast to their attributions for success); practice managers' enablers were most frequently coded under staff focus, while for practice nurses, interdependence was most frequently coded. 

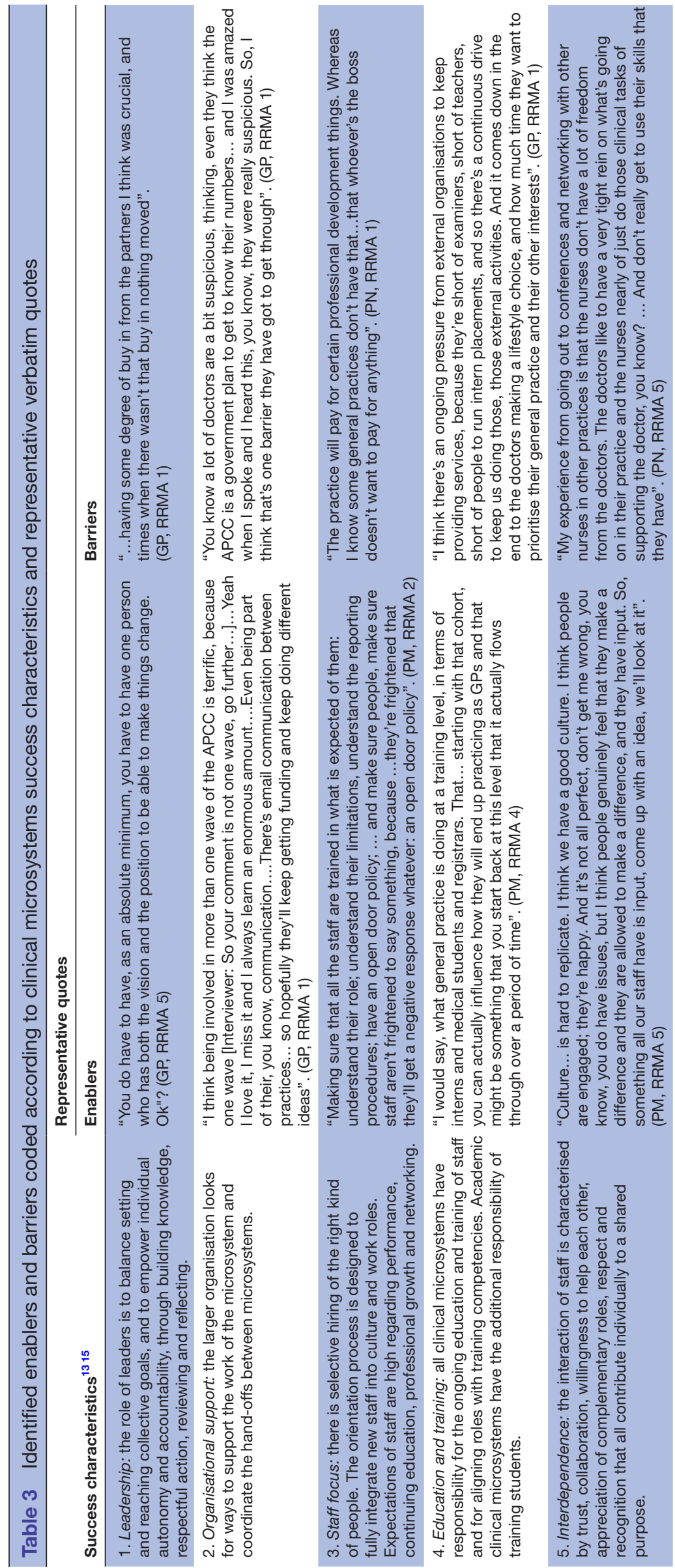

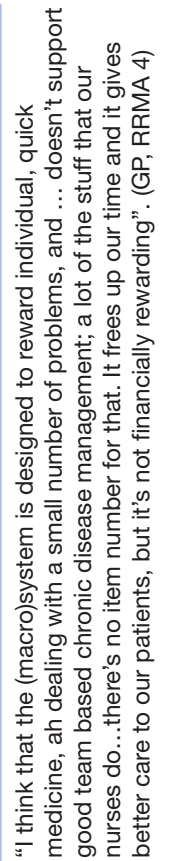
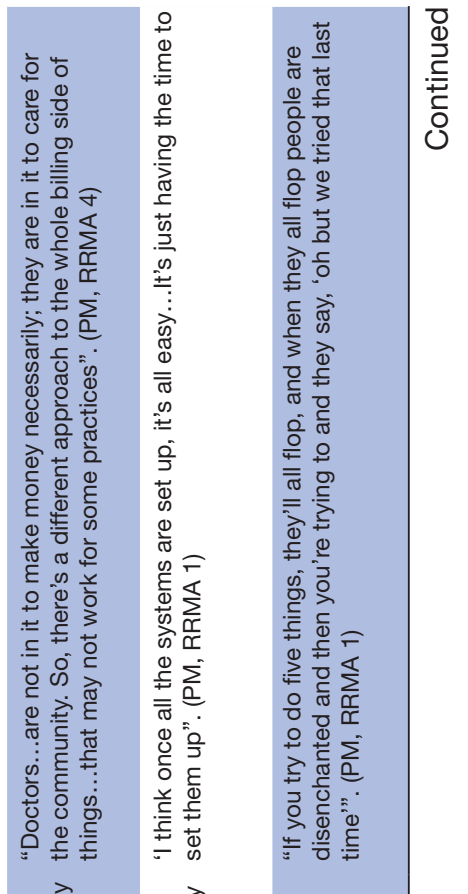

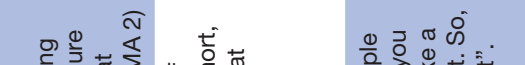

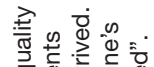

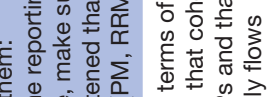

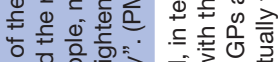

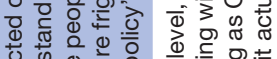

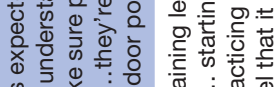

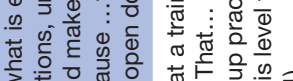

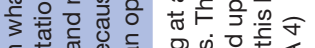

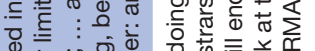

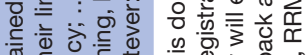

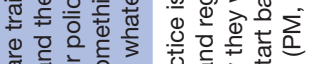

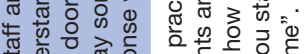

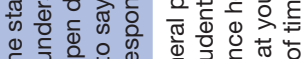

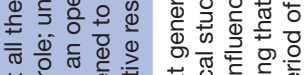

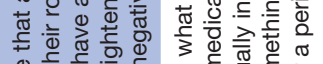

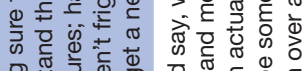

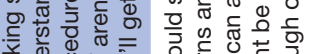

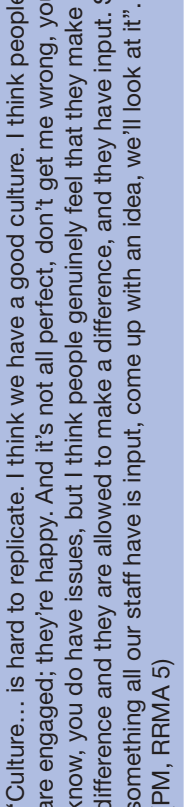

年

离

ते

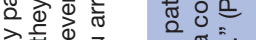

每

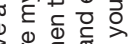

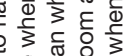

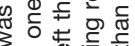

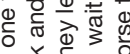

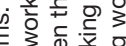

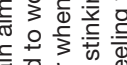

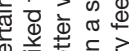

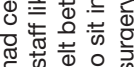

言足:

然造

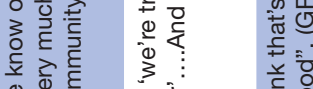

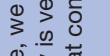

焉空

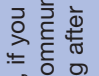

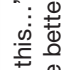

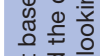

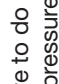

离

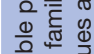

的 क

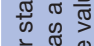

政

宩 旁

$2 \frac{1}{3}, \mathbb{2}$

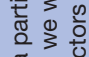

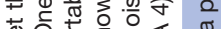

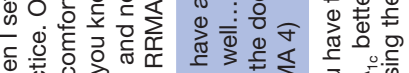

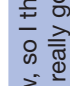

วิे

ำ

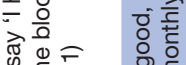

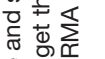

0 엄

要越

政

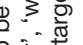

青

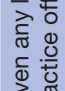

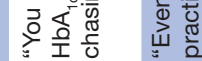
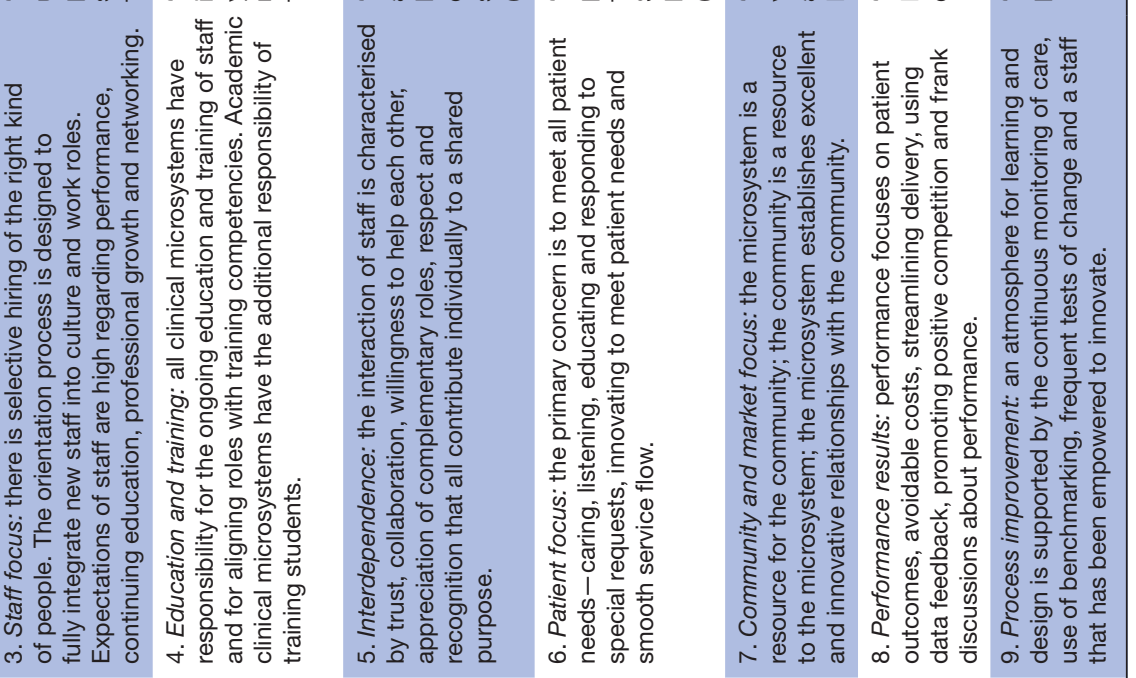

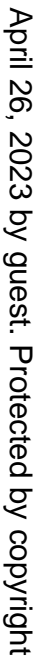




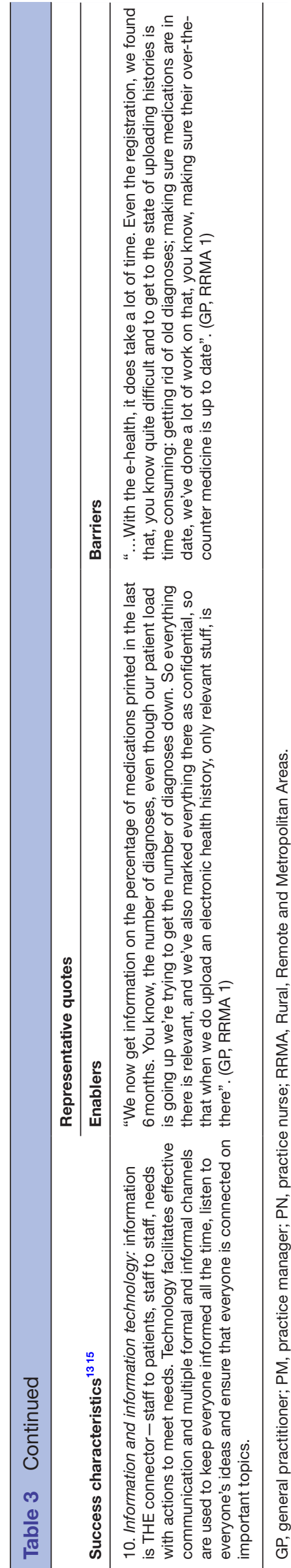

The barriers identified by participants were most frequently coded under leadership and organisational support, followed by staff focus, with performance results, education and training and community and market focus mentioned least (figure 2). Leadership was again the most frequently coded characteristic for GPs; for practice manager responses, staff focus was the most frequently used code; barriers identified by practice nurses were equally most frequently coded under leadership, organisational support, staff focus and interdependence.

\section{DISCUSSION}

When asked what made them a high-performing practice, participants most frequently articulated ideas that were strongly related to interdependence, patient focus and leadership (followed by staff focus). Nominated enablers were also attributed most frequently to leadership, followed by interdependence and staff focus. While the focus on these human characteristics might demonstrate social desirability bias (the desire to answer in a way that would be perceived favourably) and self-serving bias (aiming to maintain and enhance self-esteem) by highlighting participants' own role in accomplishing success, the significant role that each plays in ensuring continuous improvement needs to be recognised. The honesty and trust demonstrated in references to the importance of interdependence have helped to create cultures of learning and improvement where they can collectively improve things and where hierarchical boundaries need not apply so widely. ${ }^{1920}$ Inclusive teams require the inclusive leadership described by Nembhard and Edmondson ${ }^{21}$ :

Our research suggest leader inclusiveness-words and deeds by leaders that invite and approve others' contributions-can take nature off its course, helping them to overcome status' inhibiting effects on psychological safety.... We thus suggest that active, inclusive behaviour on the part of physician leaders may be an essential means of facilitating others' meaningful engagement in team-based quality improvement work. (p. 958)

Leadership holds a prominent place in our collective consciousness and has been recognised as a way in which we understand and make sense of organisations. ${ }^{22}$ Gerstner and Day describe an employee's relationship with their leader, supervisor or boss as 'a lens through which the entire work experience is viewed' (p. 840). ${ }^{23}$ Those who were not positioned as overall practice leaders (most practice managers and practice nurses), were much more likely to provide reasons for success that could be coded to leadership. Leadership may be a salient success characteristic for practice managers in particular as they depend on the support of the practice leadership to initiate organisational change. GPs may have omitted to mention this success factor because 


\section{Indentified Barriers and Enablers by Professional Group}

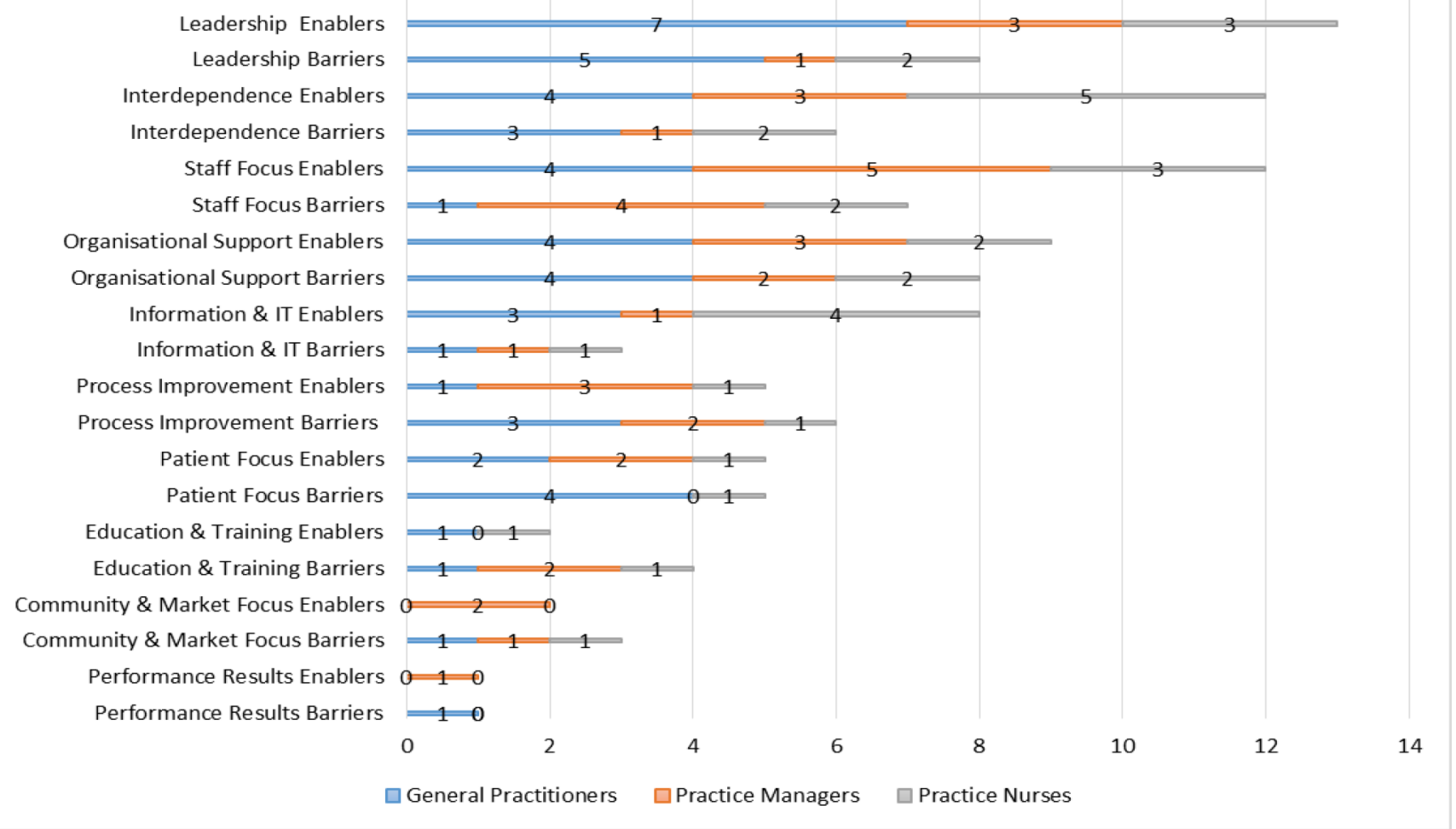

Figure 2 Identified enablers and barriers by professional group.

they assume it, or are reticent to 'talk themselves up'. GPs most frequently nominated leadership as an enabler demonstrating that they do not underestimate its importance, while they most frequently attributed success to having a patient focus. This patient focus may also be communicated in other ways including as a vision to inspire their teams to high performance, a characteristic indicative of effective leadership styles such as transformational leadership. ${ }^{24}{ }^{25}$ At the same time, the leader-consciousness of team members other than GPs is a reminder of the need for practice leaders to demonstrate and set the tone for inclusiveness.

While we do emphasise the importance of leadership in this section, all team members in effect, contribute to success and this is underlined by attributions made by all roles to 'interdependence'. We also acknowledge that leadership was referred to in terms of the GP role and attributed to other staff who headed up various teams within the practice, for example, practice nurses. Healthcare transformation is said to emerge from the persistent accumulation of small gains made at the microsystem level, the result of internal design work carried out by a multidisciplinary team. ${ }^{26}$ Those teams need to be empowered to lead change efforts, to create shared norms and values aligned with organisational goals and to incorporate routinised processes of change that involve a shared vocabulary and understanding. ${ }^{26}$ As Bohmer notes 'in effect, instead of taking their work context as a given, staff actively create the local system needed to provide the best possible care' (p. 711). ${ }^{26}$

Practice leaders could also note that while participants often acknowledged barriers to success in terms of the cost and time involved in various initiatives, they also tended to frame these costs as a necessary 'investment' in order to achieve long-term returns. Examples included educating medical staff for future roles as GPs and investments of time or finance made across a number of practice areas. This tendency might illustrate the optimism and 'calculated risk taking' that are said to comprise resilience, a noted habit of 'improvers'. ${ }^{27}$ This mindset may be a key enabler for those wishing to model themselves on these high-performing practices.

The participating general practice teams show innovation, creativity, motivation and high morale, but they would be the first to say that there is room for improvement. Our study suggests that consideration of community and market focus may be least in the minds of even high-performing practices. There was some frustration expressed about the lack of mesolevel support for community outreach initiatives. Information technology was also cited infrequently as a reason for success, although cited moderately frequently as an enabler. There is frustration with the performance of information technology in Australian general practice which while solving some problems, is also seen to generate others ${ }^{28}$ and there is a perception of low 
levels of support for this area from mesoorganisations. ${ }^{29}$ Perhaps then it is no surprise that organisational (or mesosystem) support was the second least coded reason for success. Indeed, support was not attributed to the mesoorganisation but to APCC and AGPAL. The support offered by the APCC in the form of training and development, and support for improvement and innovation was mentioned frequently as an enabler. While acknowledged as a significant resource, participants also identified perceived and real barriers to participation in this programme for other practices. Unfortunately, the most significant barrier is that funding for the APCC has been discontinued since the time when the interviews were conducted, leaving a gap in the system which needs to be filled especially as APCG was so valued by practices. The lack of mesosystem support was also illustrated in terms of time and cost barriers identified for many of the 'success characteristics'. While many of the participants were committed to investment of both resources with a view to long-term positive outcomes, these still pose very real obstacles and may indicate 'outmoded theories of control'. Alternative strategies may be called for. In response to the burden from chronic disease, a number of countries including Australia, Canada, New Zealand and the USA are moving towards patient-centred medical homes also known as healthcare homes. ${ }^{30}$ A similar Dutch development has been made through bundled payments. ${ }^{9}$ One US study found that many practices were not yet ready to perform as patient-centred medical homes ${ }^{31}$ and the situation may not be any better in other countries. A look to alternative models might address unsatisfactory mesosystem support, something that is considered a weak link in delivery of high-performing primary care. ${ }^{32}$

The findings of this study acknowledge that while more satisfactory mesosystem support to facilitate improved performance is desirable, it is not enough; these strategies do not guarantee operational change at the microsystem level; it is the structures and processes at practice level that ultimately govern delivery of care. ${ }^{26}$ The success characteristics of high-performing microsystems provide a template for guiding general practices towards structures and processes that are likely to result in effective provision of care. General practices can assess themselves using the Microsystem Assessment Tool and set their own priorities for development. ${ }^{15}$ Mesoorganisations should consider internal training to better facilitate practices in line with microsystem success characteristics. One such training programme is the Dartmouth Clinical Microsystem Curriculum. ${ }^{13}$

All our high-performing practices had been part of the APCC programme, limiting the generalisability of our findings. The interviewer may have been subject to an observer-expectancy effect that may have resulted in subconsciously prompting participant responses of particular success characteristics, even though participants were not given access to the microsystem success characteristics when giving their responses. A single coder analysed the data and the decision to take a deductive approach may evoke a confirmation bias, whereby interview text was possibly coded incorrectly in order to confirm the expected validity of the clinical microsystems success characteristics. While the responses given by participants were categorised according to the clinical microsystems success characteristics, other salient characteristics may exist, for example, some of the demographic factors outlined in table 1. Context is important in health systems. Answers given by these Australian practices may vary from the views in other countries, especially in relation to the performance of mesolevel organisations and IT.

We acknowledge that the attributions of these high-performing practices are still subjective explanations. As mentioned previously, the tendency to nominate human characteristics as the reasons for success may be due to social desirability and self-serving bias. Other parts of the interview used in this study consistently yielded information about improvements or innovations practices had made that seem to support the external recognition given to them, and these accounts are planned for a later publication. These included, for example, finding new ways to serve the needs of their community to greater efficiencies in handling information and to giving all practice personnel a voice in decision making. In addition, while the attributions made would seem to indicate likely contributions to success, if we were to also include poor performing practices in our study we might find that they too report some of the same characteristics that high-performing practices do, while their weaker performance on other characteristics impinge on their overall performance. As in the case of the participating practices, poor performing practices will not be strong in all of the success characteristics. It may be that the areas they are weak in (eg, leadership) undermine the strengths they do have. Furthermore, there may be other characteristics that can be attributed for the success of these practices that were not known or articulated by participants in the study. Finally, while we have tried to provide an external benchmark of high-performing general practices through the criteria described earlier in this paper, we acknowledge that there are other definitions of high performance that might lead to other general practices being included in such a study. For example, a patient and consumer group's view of what constitutes high performance in general practice is an obvious consideration for future research.

The study's results suggests that human dynamics remain at the forefront of our thinking in change management initiatives with learning and development approaches that harness these dynamics effectively as paramount. The key ingredients for success are a clinical microsystem consisting of inclusive leadership and an interdependent team who are committed to 'improvement and innovation' and who are empowered to accomplish just that. 


\section{Author affiliations}

${ }^{1}$ School of Population Health, Faculty of Medical and Health Sciences, University of Auckland, Auckland, New Zealand

${ }^{2}$ Deakin Rural Health School of Medicine, Faculty of Health, Deakin University, Warrnambool, Victoria, Australia

${ }^{3}$ Center for Healthcare Studies, Feinberg School of Medicine, Northwestern University, Chicago, Illinois, USA

${ }^{4}$ School of Nursing and Midwifery, Flinders University, Adelaide, South Australia, Australia

${ }^{5}$ Faculty of Health Sciences and Medicine, Bond University, Gold Coast, Queensland, Australia

${ }^{6}$ Improvement Foundation, Adelaide, South Australia, Australia

Acknowledgements The authors acknowledge AGPAL and the APCCP for their assistance in recruiting participants and the general practices that participated in this study.

Contributors Study conceived by JAD, JKJ, JF, MM and DF who also developed the interview questions. AHD analysed the data. AHD and JAD drafted the manuscript. $A H D, J A D, J K J, J F, M M$ and DF all commented on the manuscript.

Funding The research reported in this article was funded by a grant from the Australian Government Department of Health.

Disclaimer The information and opinions contained in it do not necessarily reflect the views or policy of the Australian Primary Health Care Research Institute (APHCRI), the Australian Government or the Department of Health.

Competing interests None declared.

Patient consent Not required.

Ethics approval Flinders University Social and Behaviour Ethics Committee (Project No. 5609).

Provenance and peer review Not commissioned; externally peer reviewed.

Data sharing statement Supplementary data consisting of appendices will be made available.

Open Access This is an Open Access article distributed in accordance with the Creative Commons Attribution Non Commercial (CC BY-NC 4.0) license, which permits others to distribute, remix, adapt, build upon this work non-commercially, and license their derivative works on different terms, provided the original work is properly cited and the use is non-commercial. See: http://creativecommons.org/ licenses/by-nc/4.0/

(c) Article author(s) (or their employer(s) unless otherwise stated in the text of the article) 2018. All rights reserved. No commercial use is permitted unless otherwise expressly granted.

\section{REFERENCES}

1. World Health Organization. Global action plan for the prevention and control of noncommunicable diseases 2013-2020. Geneva: World Health Organization, 2013.

2. Macinko J, Starfield B, Shi L. The contribution of primary care systems to health outcomes within Organization for Economic Cooperation and Development (OECD) countries, 1970-1998. Health Serv Res 2003;38:831-65.

3. Berwick DM. Improvement, trust, and the healthcare workforce. Qual Saf Health Care 2003;12(Suppl 1):448-52.

4. Gauld R, Mays N. Are New Zealand's new primary health organisations fit for purpose? BMJ 2006;333:1216-8.

5. Dunbar JA. When big isn't beautiful: lessons from England and Scotland on primary health care organisations. Med J Aust 2011;195:219-21.

6. Naylor C, Curry N, Holder H, et al. Supporting improvement in general practice? London: the King's fund, 2013.
7. Sorrell BR, Rosen R, Smith J. GP commissioning: insights from the medical groups in the United States. London: Nuffield Trust, 2011.

8. Abou Elnour A, Dunbar J, Ford D, et al. General practices' perspectives on medicare locals' performance are critical lessons for the success of primary health networks. Australas Med J 2015;8:320-4.

9. Struijs JN, Baan CA. Integrating care through bundled payments-lessons from The Netherlands. N Engl J Med 2011;364:990-1.

10. Oldham J. Sic Evenit ratio ut componitur: the small book about large system change. Chichester: Kingsham Press, 2004.

11. Knight AW, Caesar C, Ford D, et al. Improving primary care in Australia through the Australian primary care collaboratives program: a quality improvement report. BMJ Qual Saf 2012;21:948-55.

12. Dunbar JA, Reddy P, McAvoy B, et al. The contribution of approaches to organisational change in optimising the primary health care workforce. Canberra: Australian Primary Health Care Research Institute, 2007.

13. Nelson EC, Batalden PB, Huber TP, et al. Success characteristics of high performing microsystems: learning from the best. In: Nelson EC, Batalden PB, Godfrey MM, eds. Quality by design: a clinical microsystems approach. San Francisco: Jossey Bass, 2007.

14. Quinn JB. Intelligent enterprise: A knowledge and service based paradigm for industry. New York: Free Press, 1992.

15. Johnson JK. Clinical microsystem assessment tool. Microsystem academy. 2003 http://clinicalmicrosystem.org/wp-content/uploads/ 2014/07/microsystem_assessment.pdf (accessed Jan 2018).

16. Orlikowski WJ, Baroudi JJ. Studying information technology in organizations: research approaches and assumptions. Inf Syst Res 1991;2:1-28.

17. AGPAL. Celebrating practice achievements. https://www.agpal.com. au/practice-accreditation/ (accessed Jan 2018).

18. QSR International Pty Ltd. NVivo qualitative data analysis software. Version 11, 2015

19. Edmondson AC, Dillon JR, Roloff KS. Three perspectives on team learning. Acad Manag Ann 2007;1:269-314.

20. Schein EH, Schein P. Organisational culture and leadership. 5th edn. Hoboken, NJ: Wiley, 2017.

21. Nembhard IM, Edmondson AC. Making it safe: the effects of leader inclusiveness and professional status on psychological safety and improvement efforts in health care teams. J Organ Behav 2006;27:941-66.

22. Meindl JR, Ehrlich SB, Dukerich JM. The romance of leadership. Adm Sci Q 1985;30:78-102.

23. Gerstner CR, Day DV. Meta-analytic review of leader-member exchange theory: correlates and construct issues. J Appl Psychol 1997;82:827-44.

24. Avolio BJ. Full leadership development: Building the vital forces in organizations. Thousand Oaks, CA: Sage, 1999.

25. Bass BM, Avolio BJ. The implications of transactional and transformational leadership for individual, team, and organizational development. ROCD 1990;4:231-72.

26. Bohmer RM. The hard work of health care transformation. N Engl J Med 2016;375:709-11

27. Lucas B, Nacer H. The habits of an improver: thinking about learning for improvement in healthcare. London: Health Foundation, 2015.

28. Henderson J, Miller G, Britt H, et al; The effect of computerisation on the quality of care in Australian general practice. Final report to the royal Australian college of general practitioners. Sydney: University of Sydney, 2007.

29. Ghosh A, McCarthy S, Halcomb E. Perceptions of primary care staff on a regional data quality intervention in Australian general practice: a qualitative study. BMC Fam Pract 2016;17:50.

30. Janamian T, Jackson CL, Glasson N, et al. A systematic review of the challenges to implementation of the patient-centred medical home: lessons for Australia. Med J Aust 2014;201(3 Suppl):69-73.

31. Hollingsworth JM, Saint S, Sakshaug JW, et al. Physician practices and readiness for medical home reforms: policy, pitfalls, and possibilities. Health Serv Res 2012;47(1 Pt 2):n/a-508.

32. Rosen R, Kumpunen S, Curry N, et al. Is bigger better? Lessons for large-scale general practice. Research report: Nuffield Trust, 2016. 